\title{
Squeak Etoys na modalidade 1 para 1: programação e autoria multimidia no desenvolvimento da conceituação
}

\author{
Title: Squeak Etoys in 1 to 1 (one computer per student) learning modality: \\ programming and multimedia authoring for developing students' conceptualization
}

\author{
Bruno Fagundes Sperb \\ Programa de Pós-Graduação em Psicologia Social e \\ Institucional - Universidade Federal do Rio Grande do Sul \\ (UFRGS) \\ bruno@lec.ufrgs.br
}

\section{Léa da Cruz Fagundes}

Programa de Pós-Graduação em Informática na Educação

- Universidade Federal do Rio Grande do Sul (UFRGS)

leafagun@ufrgs.br

\author{
Patrícia Behling Schäfer \\ Programa de Pós-Graduação em Informática na Educação \\ - Universidade Federal do Rio Grande do Sul (UFRGS) \\ patricia@lec.ufrgs.br
}

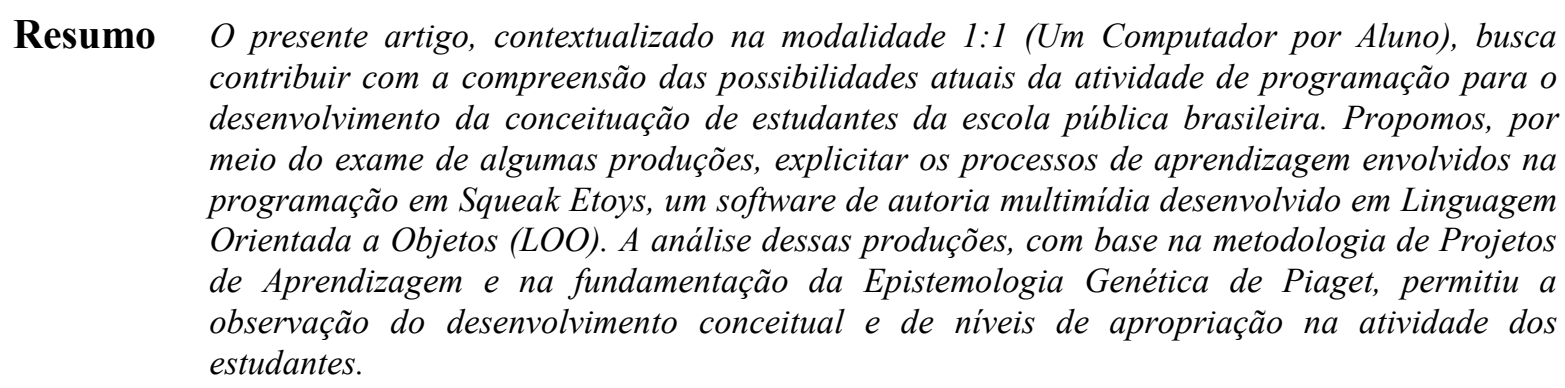

Palavras-Chave: Squeak Etoys; atividade de programação; aprendizagem; conceituação; Epistemologia Genética.

\begin{abstract}
This paper, contextualized by "1:1" (One Laptop per Child) learning modality, aims to contribute to the understanding of the current possibilities of programming activity for conceptualization development of public school students in Brazil. We propose, through the examination of some children's productions, to explicit learning processes involved in programming with Squeak Etoys, a multimedia authoring software developed in ObjectOriented Language. The analysis of these productions, based on the methodology of Learning Projects and supported by Piaget's Genetic Epistemology, allowed the observation of the conceptual development and ownership levels in the activities of students.
\end{abstract}

Keywords: Squeak Etoys; programming activity; learning; conceptualization; Genetic Epistemology. 



\section{Introdução}

Em meados da década de 1970, Seymour Papert introduz o estudo da atividade de programar como meio de auxílio à educação. A realidade atual da escola, no entanto, aponta que as possibilidades oferecidas ao aluno para explorar sistemas complexos, programar, construir de forma autônoma produtos digitais ainda são raras. E por que essas dificuldades permanecem? Parece haver consenso entre diversos pesquisadores da Informática na Educação em relação à ideia de que o uso do computador na escola está ainda a serviço de reproduzir antigos métodos de ensino [1, 2, 3]. Resnick [4] sustenta que há a necessidade de repensar tanto as abordagens de aprendizagem na escola quanto a proposta de suporte das novas tecnologias a essa mudança.

Desde dezembro de 2006, o Laboratório de Estudos Cognitivos do Instituto de Psicologia da Universidade Federal do Rio Grande do Sul (LEC/UFRGS) participa do programa federal Um Computador por Aluno (PROUCA) [5]. A iniciativa investiga a possibilidade de adoção de laptops de baixo custo pela rede pública de ensino como um meio de promover a melhoria da qualidade da educação brasileira. Entre 2007 e 2009, o laboratório foi responsável pela execução do pré-piloto do estado do Rio Grande do Sul (uma das cinco experiências da primeira fase do programa).

Durante esse período, foram constituídas diferentes linhas de investigação e acompanhamento das ações de alunos e professores, buscando examinar os aspectos técnicos e pedagógicos envolvidos na adoção da modalidade de aprendizagem "um computador por aluno" (1 para 1). Como proposta integradora das diferentes unidades de análise estabelecidas, elencou-se a metodologia de Projetos de Aprendizagem - PAs [2], em cuja fundamentação estão os princípios da Epistemologia Genética $[6,7,8,9]$. Na metodologia de PAs, o aluno é concebido como agente-autor, vivenciando um processo semelhante ao da investigação científica, ao formular perguntas, buscar respostas e elaborar teorias explicativas para temas de seu interesse. O professor, por sua vez, alia à função de especialista os papéis de orientador, articulador e ativador da aprendizagem do aluno.

Uma das frentes de investigação na escola polo do pré-piloto do Rio Grande do Sul (E.E.E.F. Luciana de Abreu, Porto Alegre) teve como suporte o trabalho com o ambiente de autoria multimídia Squeak Etoys [10]. O ambiente foi desenvolvido por Alan Kay e a equipe do View Points Research Institute, ${ }^{1}$ sob inspiração dos

$1 \quad$ VIEWPOINTS

RESEARCH

INSTITUTE.

(2011) sistemas LOGO, PARC-Smalltalk, Hypercard, StarLOGO e grande influência das ideias de Papert [11].

A utilização do programa pelo LEC/UFRGS passou a integrar uma estratégia de multiplicação com vistas a alcançar diversos grupos de alunos e professores no Brasil e também em âmbito internacional. Na primeira etapa do PROUCA, foram desenvolvidas experiências com aproximadamente 100 alunos e diversos professores da escola polo Luciana de Abreu. As experiências e discussões provenientes do trabalho com o ambiente geraram sustentação para a organização do Squeakfest Brasil [12]. O Squeakfest Brasil foi a primeira edição da conferência internacional dedicada ao estudo do ambiente realizada fora dos Estados Unidos, que reuniu, além de pesquisadores brasileiros, representantes da equipe de desenvolvimento do Squeak Etoys e educadores que lideram comunidades internacionais de uso do ambiente, sobretudo no Uruguai, nos Estados Unidos e na Alemanha. Mais recentemente, desde o início de 2011, o LEC/UFRGS vem realizando oficinas semanais voltadas ao uso do Squeak Etoys com alunos e professores de duas turmas de terceiro ano (do ensino fundamental de nove anos) da E.E.E.F. Profa. Dinah Néri Pereira, localizada em Porto Alegre, que conta em sua prática com laptops do modelo XO, por meio de uma parceria estabelecida com a organização OLPC (One Laptop Per Child, MIT Media Lab). Além disso, a aplicação educacional do ambiente é incluída na formação continuada de professores da segunda fase do PROUCA na região de abrangência da coordenação do LEC/UFRGS.

Buscaremos, neste artigo, abordar a pertinência da utilização do ambiente Squeak Etoys, contextualizada na metodologia de PAs aplicada em uma turma de quarta série, para o acompanhamento e auxílio ao desenvolvimento conceitual de alunos segundo a perspectiva da Epistemologia Genética de Piaget e orientação do método clínico-crítico também proposto pelo autor [13]. Pretendemos, por meio deste e de futuros trabalhos, consolidar referências para a ampliação do uso educacional do ambiente e a consequente disseminação de suas possibilidades para o processo de aprendizagem.

\section{Breve caracterização de Linguagens Orientadas a Objetos}

Cada linguagem de programação apresenta uma certa identidade, a que podemos chamar de paradigma no qual foi desenvolvida. Essa identidade define a forma como o programador pensa a própria atividade de programar.

Conforme referido anteriormente, o desenvolvimento do ambiente Squeak Etoys foi inspirado inicialmente em 
sistemas como o LOGO e o StarLOGO. Contudo, há características do paradigma de LOO (Linguagens Orientadas a Objetos) que diferenciam o ambiente de seus antecessores.

Enquanto no paradigma de Linguagem Procedural $^{2}$ as ações sobre os objetos são executadas por comandos sequenciais ou "o programa representa a prescrição da solução para o problema" [14] (p. 2), uma LOO possibilita a programação simultânea de múltiplos objetos no "mundo".

Em uma linguagem orientada a objetos, há a ideia central de que uma unidade, ou "objeto", é uma parte autônoma do sistema, mas tem as propriedades de seu todo, recursivamente. Segundo um de seus criadores, Alan Kay [15]: "uma descrição de todo o modelo é necessária para gerar a representação de uma de suas partes" (p. 6). Cada um desses objetos, então, "herda" as propriedades fundamentais do próprio sistema (assim como também de outros objetos) em que está inserido. Em outras palavras, uma forma de explicar o princípio da linguagem seria a divisão do computador (conceitualmente, através de seus poderes de simulação) em vários outros computadores, ou objetos, para cada qual poderia ser conferido um papel, como a um ator de uma peça [15].

Assim como referido por Papert [16], uma LOO dá ênfase à relação entre objetos, ou ao processamento de múltiplos objetos. Em relação ao contexto deste trabalho - a atividade de programação da criança - cabe apenas lembrar que os conceitos brevemente expostos fazem parte da concepção de LOO e, consequentemente, do ambiente Squeak Etoys.

\section{0 ambiente Squeak Etoys}

O Squeak Etoys é um software livre que permite ao usuário criar muitos tipos de objetos: apresentações, textos, livros, vídeos, sons, etc. A ideia que norteia o programa é a de que seja o mais aberto possível, com o maior número de ferramentas disponíveis para o usuário, não apenas para acesso, como também para programação. Assim, estabelece um contraponto à fragmentação geralmente imposta pelos programas computacionais (como, por exemplo, diferentes softwares "de escritório", com funções específicas e bem delimitadas).

No que tange ao funcionamento, tudo o que é criado no Squeak Etoys se torna um objeto. Todo objeto, por sua vez, é maleável, manipulável e apresenta um determinado número de propriedades. $\mathrm{O}$ ambiente possibilita ao

\footnotetext{
2 A descrição refere-se ao princípio da concepção da Linguagem Procedural conforme caracterização de Papert em "Mindstorms: Children, Computers and Powerful Ideas" (1980).
}

usuário tanto manipular os objetos em sua forma, através de funcionalidades básicas (mudar largura, altura, duplicá-lo, etc.), quanto programá-los por meio de scripts (proposições de programação). A figura 1 exibe a tela inicial do ambiente, ela própria manipulável pelo usuário. São apresentados, na tela inicial, o menu de aplicações, tutoriais desenvolvidos a partir do ambiente, demonstrações de produções em Squeak Etoys e o link para a realização de um novo projeto.

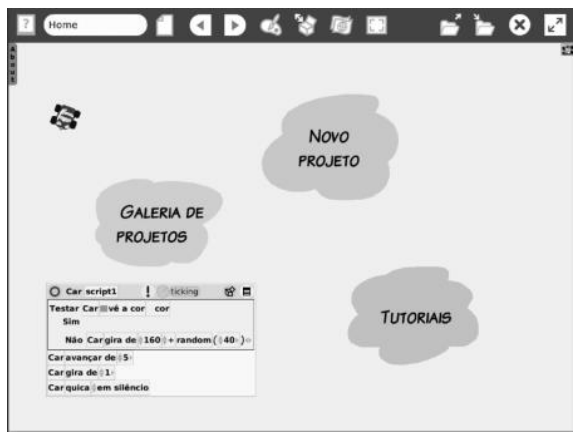

Figura 1: Tela inicial do Squeak Etoys

O Squeak Etoys, por si só, não instrui e não possui ferramentas definidas que guiem desde o princípio o pensamento do aluno. Uma criança pequena, por exemplo, pode fazer apenas um desenho simples, ou escrever algumas letras ou palavras. Outra pode realizar um projeto de simulação do comportamento de um animal, animar uma história em quadrinhos ou o movimento dos astros. Faz-se possível, assim, criar desde produtos digitais básicos até projetos e simulações de alta complexidade; em outras palavras, o ambiente permite que o próprio aluno "ensine" ao computador e ensine a outro aluno como fazê-lo.

Essa concepção de ambiente computacional é consonante com a Epistemologia Genética de Piaget [6, 7, $8,9]$, segundo a qual o conhecimento se dá pela interação com o meio: o sujeito age sobre o objeto assimilando-o e reage às ações que este lhe impõe. Quando os sistemas de esquemas de que dispõe mostram-se insuficientes, a assimilação promove perturbações e exige transformações também internas, que acontecem através da acomodação. Há sempre uma organização presente na base da ação, que mobiliza o funcionamento das estruturas mentais rumo a um processo de construção progressiva. Só há conhecimento mediante construção, e esta ocorre por experimentação ativa e constante das hipóteses do sujeito, colocadas em prática no ambiente com o qual interage.

Objetivamos, aqui, realizar uma breve apresentação do ambiente Squeak Etoys com fins de ilustração para as seções posteriores do trabalho. Lembramos, no entanto, que o acompanhamento do desenvolvimento da inteligência da criança em ambiente computacional de programação, em especial por meio da linguagem LOGO, 
tem sido largamente explorado por diversos pesquisadores do LEC/UFRGS [17, 18, 19] e de outros centros de pesquisa ao longo dos últimos trinta anos. O Squeak Etoys é, portanto, fruto de uma longa trajetória de investigação da aplicação da informática e da atividade de programação para o auxílio à aprendizagem da criança, no contexto de uma cultura da computação especificamente educacional.

\section{Construindo o conceito: ação, representação, operação}

Piaget [9] trata da gênese e construção do conceito considerado em seu caráter sistêmico e relacional. Busca as conexões entre a atividade sensório-motora, a função simbólica e as formas operatórias do pensamento.

As formas de pensamento representativo possibilitam ultrapassar o campo perceptivo imediato para evocar em pensamento objetos ausentes. Trata-se do nascimento da função simbólica ou semiótica. Contudo, os esquemas da inteligência sensório-motora não são imediatamente transformados em conceitos, tampouco as primeiras coordenações em raciocínios operatórios. No nível das operações lógicas concretas, os conceitos são ora sistemas de classes, constituindo agrupamentos segundo relações de encaixe hierárquicos, ora sistemas de relações particulares, que não seguem o conjunto dos elementos e das transformações, nem possíveis coordenações de relações. $\mathrm{O}$ alcance do pensamento operatório - e do conceito - é marcado pela coordenação em equilíbrio permanente, com a possibilidade de realização de antecipações e reprodução de transformações objetivas por experiência mental. É também característica do princípio do desenvolvimento do conceito a capacidade de socializar as construções empreendidas com o suporte dos signos sociais e coletivos.

Piaget [7] destaca que o caráter inicial da ação é de conhecimento prático e autônomo, ainda independente da conceituação. As primeiras coordenações realizadas pela criança são, igualmente, coordenações de natureza material e visual. Apenas no decurso de seu desenvolvimento, são alcançadas as coordenações implicativas ou ligações entre significações. As tomadas de consciência elementares são, dessa forma, ligadas aos objetivos e resultados das ações, enquanto que as tomadas de consciência de nível superior comportam implicações significantes, que favorecem a reflexão e a análise dos meios empregados.

Ao trabalharem no ambiente de autoria Squeak Etoys, os alunos encontram a necessidade constante de pensar e de falar sobre o que pensam e desejam fazer. O Etoys passa a lhes servir como um instrumento para a representação dos elementos da ação. Em relação à tal modalidade de ambiente de programação, é substancial a contribuição de Nevado [18], para quem "o raciocínio da criança pode ser mais facilmente 'observado', já que o micromundo 'concretiza' suas formas de pensar em situações variadas e criadas pela própria criança” (p. 82). A autora, ao escrever sobre experiências realizadas com crianças a partir da utilização da linguagem LOGO, pondera que, ainda que de posse da função semiótica, os sujeitos, frente ao computador, tendem a refazer a trajetória já realizada no período sensório-motor (num período de tempo mais curto e variável segundo o nível de desenvolvimento individual). Outro aspecto importante no que tange à opção pelo trabalho com o ambiente de micromundos para o acompanhamento e auxílio à conceituação é a possibilidade de realização de intervenções que oportunamente conduzam a criança a tomadas de consciência sobre suas ações para o alcance de níveis mais complexos de integração em sistemas de significações. No Etoys, a mobilidade e flexibilidade no manejo de scripts para a programação de um objeto facilitam a verificação de antecipações e do sucesso ou insucesso das deduções sobre o possível.

Na próxima seção, faremos a análise de uma produção no ambiente Etoys em cujo processo de construção são observados indicadores de conceituação e momentos de intervenção que precedem ou se fazem acompanhar de tomadas de consciência para o desenvolvimento rumo ao pensamento operatório.

\section{Conceituação no Squeak Etoys: representando e programando a partir de PAs}

Durante o trabalho de acompanhamento das atividades do PROUCA na escola Luciana de Abreu, a equipe de pesquisadores do LEC/UFRGS ofereceu oficinas de aprendizagem em que alunos e professores exploraram os recursos do Squeak Etoys. Inicialmente, essas oficinas eram ministradas para turmas inteiras, às quais era possibilitado o uso de diversas ferramentas do programa. A forma como cada professor trabalhava, integrando em maior ou menor grau atividades em ambiente digital ao seu cotidiano, oportunizou que, ao longo da experiência, ocorressem mudanças no modelo oferecido nas oficinas. $\mathrm{Na}$ turma de quarta série, a prática pedagógica diária, já nos primeiros meses do projeto, passou a centrar-se na metodologia de PAs. Assim, houve uma transição do modelo massivo de ensino, em que todos os alunos realizavam a mesma atividade ao mesmo tempo e no mesmo espaço, para um trabalho guiado por projetos desenvolvidos pelos próprios alunos, reunidos a partir de diferentes problemas de pesquisa.

Dessa forma, o trabalho nas oficinas passou a ser 
realizado em pequenos grupos, em sala contígua à da turma. Havia uma discussão acerca do problema de pesquisa do grupo para que os alunos pensassem sobre seus objetivos e sobre como usar o ambiente Squeak Etoys em seus projetos, com base na exploração de seu conhecimento e de suas hipóteses iniciais [20]. As oficinas tinham duração de aproximadamente uma hora e trinta minutos, e eram registradas pelos pesquisadores por meio de vídeo e fotografia, para posterior análise.

O projeto que constitui o fio condutor da presente análise foi desenvolvido por um grupo de alunos que buscava investigar como havia ocorrido a explosão do "Big Bang"," A pergunta de pesquisa foi elaborada espontaneamente pelo grupo, conforme $\mathrm{o}$ interesse demonstrado, constituindo a base para posteriores intervenções da professora (uma delas a própria sugestão de participação do grupo na oficina). Os alunos, então, procuram os pesquisadores para manifestar seu desejo de participarem de um encontro para a atividade de programação. Estabelecemos um diálogo no início da oficina, em que os aprendizes exibiam interesses diferentes: o integrante VIM (10 anos), cujo processo detalharemos a seguir, buscava representar a formação da Terra a partir do fenômeno.

Inicialmente, o pesquisador solicita ao aluno VIM que explique sua intenção ao elaborar o projeto. Observa-se que, a partir do conhecimento inicial desenvolvido nas oficinas introdutórias para a apropriação do Etoys, o aluno consegue, de forma independente, desenhar as partículas que desencadearão o "Big Bang", bem como acionar o seu movimento. Separadamente, VIM desenha a forma de uma explosão. O desafio encontrado, e compartilhado com os pesquisadores, era fazer com que o desenho da explosão se tornasse visível apenas no momento do choque entre as duas partículas. O desejo do aluno ao construir sua representação e o processo inicial empreendido são relatados por VIM:

Primeiro eu abri o script de uma, dai eu fechei, daí ela começou a girar sozinha, depois eu peguei outra e abri o script de outra, dai eu trouxe e fiz o script da segunda. Botei a mesma coisa, dai as duas começaram a girar assim. Daí elas vão se bater assim, na hora que elas se baterem eu queria fazer uma explosão, elas vão explodir, daí vai formar o Big Bang.

A competência do aluno em socializar o seu intuito na

\footnotetext{
${ }^{3}$ A despeito da concepção mais aceita do Big Bang como expansão de um átomo primordial, responsável pela evolução e atual constituição do universo, o aluno explica o fenômeno como proveniente de uma colisão de partículas, provavelmente referindo-se às partículas elementares da matéria inicial e aos choques geradores de energia. Tal compreensão não é problematizada no início do processo, de modo a evitar coibir as manifestações de hipóteses de VIM com base nas quais construiria a simulação.
}

composição multimídia e reconstituir os passos realizados no ambiente evidencia a compreensão inicial manifesta. VIM, nesse momento, consegue construir objetos com scripts específicos, que lhes conferem movimento; sua compreensão, contudo, é apenas prática: os objetos visualmente interagem, mas não há comandos que os façam "reconhecer" um ao outro. O aluno ainda não se vale da lógica de proposições "se..., então" para estabelecer coordenação entre os objetos. O procedimento via ensaio-erro mostra-se insuficiente para o sucesso da ação. De acordo com Piaget [8], tais ações elementares "principiam por tentativas sucessivas sem qualquer plano de conjunto, para depois se tornarem cada vez mais antecipadoras, o que permite o sucesso de combinações mais complexas" (p. 20). Essa necessidade de antecipação das ações, suscitada pelo ambiente, tornase mais evidente quando VIM, espontaneamente, realiza no quadro negro o desenho que exibe a sequência de eventos que deseja simular. Essa sequência de passos, assim como a tentativa inicial de simular a explosão no ambiente, é ilustrada na figura 2.

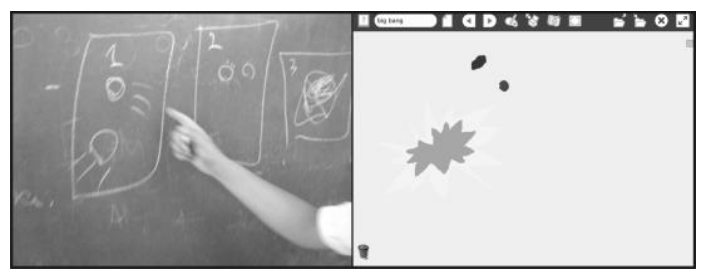

Figura 2: Sequência de passos desenhados no quadro e simulação inicial da explosão no Etoys

A intenção do aluno é expressa com clareza, embora a composição de duas proposições - "Mostrar" e "Esconder" - no mesmo script gere um conflito para o programa. Nota-se a necessidade de coordenação implicativa dos significados das duas ações (coordenação que permanece em nível prático e causal) para que o efeito buscado seja atingido. O aluno remove ora $o$ comando "Mostrar", ora o comando "Esconder", sem, no entanto, ter sucesso em sua alternância. A entrevista tem continuidade:

VIM: Olha aqui, BRU, não dá 'ó'. Eu fiz uma explosão 'tri' legal, mas não mostra... Pus aqui o esconder e o mostrar.

$P$ : $O$ que tu estás mandando esconder e mostrar? Quem é o sketch (objeto) 1?

VIM: A explosão! Sim, eu tinha feito a explosão, daí eu vim aqui e coloquei assim.

P: Então vamos abrir o script. Olha o que tu me 'disse' há pouco: "se o objeto 1..."

VIM: Encostar no objeto 2, vai acontecer uma explosão...

P: Como se faz isso? Onde está a caixa do testar? Se o objeto 1 enxerga o objeto 2, onde faz isso?

VIM: Aqui? Nas cores? 
P: E qual é a cor que tem que enxergar a cor vermelha para acontecer a explosão?

VIM: A vermelha tem que enxergar!

$P:$ A vermelha tem que enxergar a vermelha?

VIM: Não, a vermelha tem que enxergar a... Eu botei branca e tem que botar preta? Tem que enxergar a branca?

P: Onde é que tem branco aí?

VIM: Aqui (no “mundo”), mas na verdade é preto! Então o vermelho tem que enxergar o preto.

[As cores são alteradas]

P: E agora, como está? Se o preto do objeto 1 vê o vermelho, o que acontece?

VIM: Vai ter que acontecer a explosão!

No decurso do processo de alteração de cores e de tomadas de consciência sobre a própria ação, que ora acontecem mediante abstrações empíricas, vinculadas à reação imposta pelo objeto, ora via antecipações em pensamento, uma nova perturbação é colocada para VIM, por meio da sugestão do colega LMC:

LMC: Não tem que colocar a explosão lá em cima delas? Daí já aparece direto na hora que elas se batem...

VIM: Mas como é que eu vou conseguir botar bem na hora que elas batem?

P: Boa pergunta... Olha aqui, tu já 'disse' para o computador "se o preto vê a cor vermelha", então, o que tem que acontecer?

VIM: A explosão...

A sugestão do colega, a despeito de gerar um novo conflito cognitivo para VIM, é acatada, reorientando a produção. Trata-se de uma conduta compensadora importante para que a equilibração aconteça: o elemento "perturbador" não é ignorado ou negligenciado a fim de que seja submetido aos esquemas existentes, mas integrado ao sistema com vistas a uma futura regulação [6]. Ao mover a "explosão" para cima das duas partículas, no entanto, ela se torna visível permanentemente, deixando de suscitar o efeito desejado. $\mathrm{O}$ aluno solicita, assim, novo auxílio ao pesquisador:

P: Quando o objeto 1, o preto, vê a cor...

VIM: Vermelha!

P: Que acontece?

VIM: 'Cabum!'

P: A explosão fica 'mostrando'...

VIM: Ahhhh!

P: Agora, ele 'tá' vendo a cor vermelha?

VIM: Tá.

P: Qual?

VIM: Não dá pra ver... A explosão 'tá em cima!

$P$ : E qual é essa cor aqui: vermelha, da explosão?
VIM: Vermelha... Ahhhh! Tem que trocar de cor.

A conduta de egocentrismo intelectual (o aluno atribui o insucesso da "explosão" à impossibilidade de visualização da cor da partícula, quando tal impossibilidade é proveniente de seu próprio ponto de vista) é sucedida por uma tomada de consciência que responde, finalmente, pelo alcance do objetivo estabelecido. No momento em que conclui que a cor vermelha atribuída ao objeto deve ser exatamente a cor vermelha associada ao script (sem nuances na tonalidade), o aluno tem sucesso na concretização da representação planejada. Progride, assim, do desenho de duas partículas de mesma cor, com scripts simples, até a programação de partículas de cores diferentes que interagem gerando uma "explosão".

O exemplo descrito ilustra as etapas empreendidas desde as primeiras coordenações, ainda em nível perceptivo e causal, até o alcance de raciocínios operatórios por VIM. Também apresenta o processo de transição de centrações em objetos ou estados isolados para a generalização que anuncia o conceito, juntamente com a possibilidade de antecipações em pensamento e deduções sobre o possível. Destaca-se, no decurso do processo apresentado, a pertinência da utilização do ambiente Squeak Etoys fundamentada no interesse do aprendiz, propiciada pelo desenvolvimento do PA, e mediada por intervenções com orientação no método clínico-crítico [13]. É com base em tais intervenções que se pode acompanhar o pensamento do aluno e as mudanças em suas hipóteses, bem como auxiliá-lo para o alcance de tomadas de consciência que contribuam com o desenvolvimento conceitual.

\section{Introduzindo níveis de apropriação a partir das atividades iniciais}

Uma das ações voltadas ao acompanhamento dos processos de conceituação mediados pela atividade de programação na segunda fase do Programa UCA (atualmente em andamento) consiste no estabelecimento de níveis de apropriação com base no levantamento de condutas regulares observadas no decurso da exploração do ambiente Squeak Etoys pelos aprendizes. O estabelecimento de níveis e a posterior classificação das condutas empreendidas pelos alunos possibilitam o acompanhamento do desenvolvimento da conceituação, bem como o auxílio a tomadas de consciência que possam se refletir sobre progressos inferenciais e consequentes avanços em relação à própria classificação adotada.

A proposta de classificação inicial, a seguir descrita, realiza um mapeamento das primeiras condutas observadas e deverá fundamentar o quadro de análise 
para a continuidade da pesquisa.

- Nível I: as trocas do sujeito com o ambiente centram-se sobre o grafismo dos objetos, manifestando um nível figural. Se alguns objetos são criados (desenhados), frequentemente há indiferenciação em relação ao que é o "mundo" (ou fundo) e ao que é "objeto", ao que estará nele (mundo) contido, ou entre os próprios objetos. Observa-se a ausência de classes gerais ou de identidades individuais, caracterizando-se uma pré-logica ou um pré-conceito, que antecedem a possibilidade de realização de operações [9]. A proposição do ambiente de que "tudo é objeto" permanece distante da apropriação pelo sujeito. Não há, dessa forma, qualquer comunicação objetiva entre o sujeito e o objeto por ele construído, isto é, não há scripts que comandem o objeto. Há produção de símbolos, representados nos objetos criados pelo aprendiz, que guardam uma ligação subjetiva com suas ideias, mas ainda não há construções que envolvam a linguagem de programação. Igualmente, ainda não há intenção (ao menos manifesta no produto criado) do aprendiz em relação àquilo que deseja fazer, ao seu projeto (figuras 3 e 4).

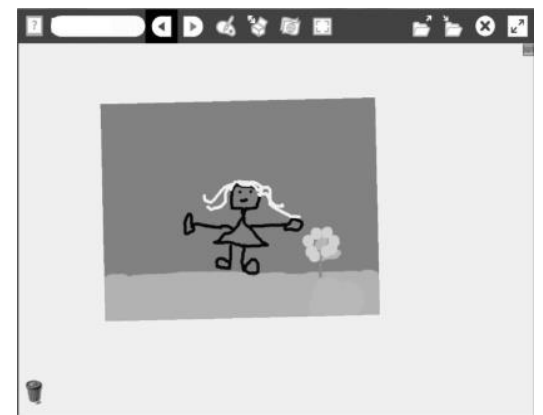

Figura 3: Desenho de "criança brincando em um jardim" (conforme descrição do aprendiz)

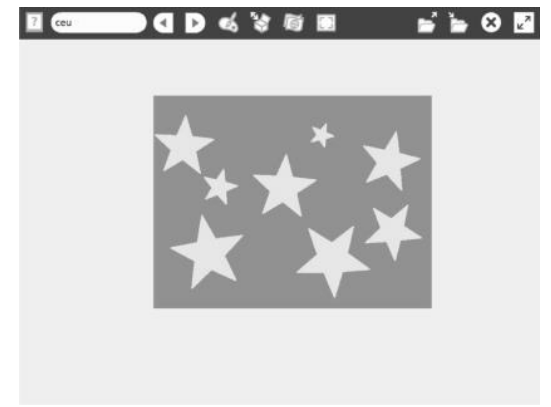

Figura 4: Desenho do "céu" (conforme descrição do aprendiz), contendo todos os elementos em um único objeto

- Nível II: há um princípio de compreensão da possibilidade de criar diferentes objetos, assim como de diferenciá-los do mundo. Há, também, uma intenção inicial da criança no sentido de conferir algum comportamento ao objeto, de fornecer-lhe "comandos", ainda que esse propósito não seja necessariamente expresso pela programação através de comandos. Observa-se, portanto, o estabelecimento de relações entre parte e todo, bem como a construção das primeiras imbricações lógicas e hierárquicas [9]. Os comandos atribuídos ao objeto, quando existentes, são na maioria das vezes aleatórios: não há relação entre o comportamento de diferentes objetos (figuras 5 e 6 ).

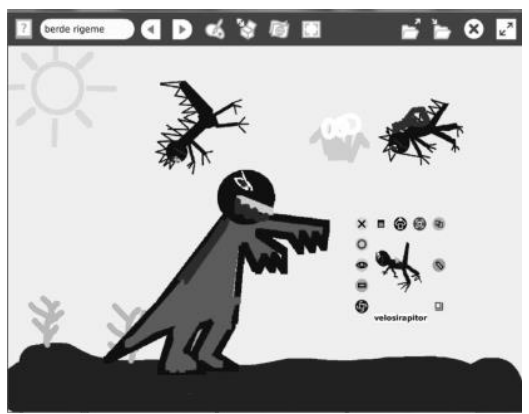

Figura 5: "O ataque" (conforme descrição do aprendiz): objetos e mundo criados e nomeados separadamente (sem programação)

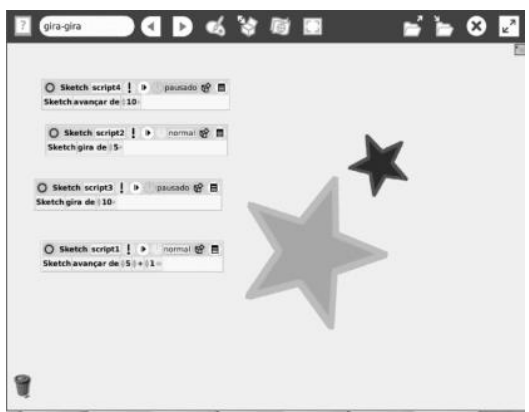

Figura 6: "Gira-gira" (conforme descrição do aprendiz): duas estrelas (um único objeto), com vários scripts criados aleatoriamente

- Nível III: o sujeito cria objetos separadamente, estabelecendo clara diferenciação em relação ao mundo. Há uma intencionalidade do aprendiz em conferir comportamentos aos objetos criados, que pode ser constatada objetivamente por meio da presença de comandos (scripts) associados aos objetos. Há, também, nesse nível, o princípio de relações entre objetos diferentes (comandos ou propriedades que se relacionam, como, por exemplo, um joystick que controla um personagem). Essas relações, em alguns casos, contêm proposições condicionais (se..., então) que vinculam diferentes objetos ou determinam $\mathrm{o}$ comportamento de um objeto através de uma condição a ser ou não satisfeita. Há, assim, o 
desenvolvimento da composição operatória, que anuncia o estabelecimento de classes e a possibilidade de realização de coordenações implicativas [7, 9]. A figura 7, por exemplo, apresenta uma produção em que objetos diferentes ("pássaro" e "ônibus") são programados por meio de scripts diferentes, que determinam (i) a animação do pássaro, (ii) o movimento do ônibus (em proposição condicional) e (iii) a relação entre o "joystick” e o pássaro. Já a produção exibida na figura 8 apresenta, conforme a descrição do aluno autor, "o jogo mais difícil do mundo ${ }^{4}$, , no qual são criados objetos diferentes ("objetos giratórios", "quadrado vermelho", "joystick", pontos de chegada e partida), com comandos próprios estabelecidos de acordo com sua função no jogo. Há relações entre objetos (joystick e "quadrado vermelho") e a clara intenção de um jogo: a chegada de um personagem (quadrado vermelho) a um objetivo, após a passagem por obstáculos.

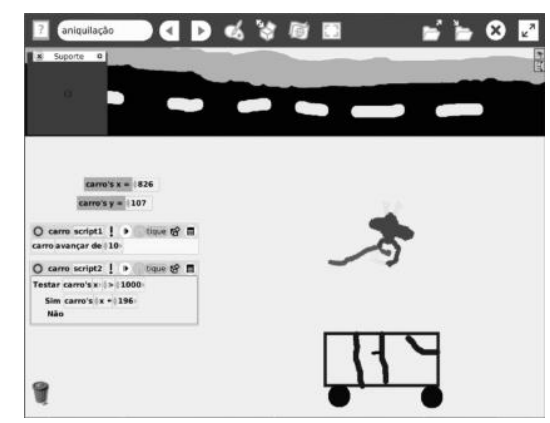

Figura 7: "Aniquilação" (conforme descrição do sujeito): programação em scripts diferentes para a animação do pássaro, o movimento do ônibus e a relação entre joystick e pássaro

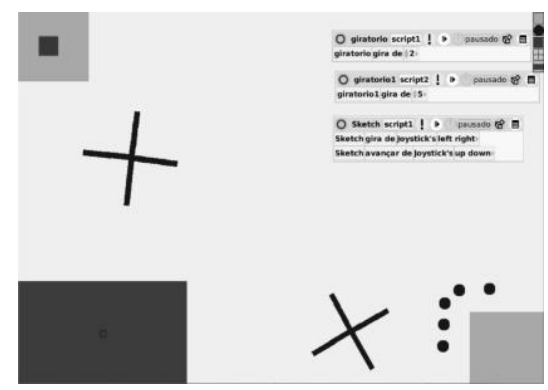

Figura 8: "O jogo mais difícil do mundo" (conforme descrição do sujeito): criação de objetos diferentes com comandos próprios estabelecidos de acordo com suas funções no jogo

Nota-se, assim, a existência de estados sucessivos que conduzem à construção do conceito e da operação. Há,

\footnotetext{
${ }^{4} \mathrm{O}$ sujeito busca realizar sua própria simulação do jogo online intitulado "Jogo mais difícil do mundo". Disponível em: $<$ http://www.o-jogo-mais-dificil-do-mundo.com/>.
}

inicialmente, um nível pré-lógico, em que faltam inferências que procedam do singular para o geral ou do geral para o singular [9], sendo caracterizado, portanto, pela ausência de diferenciações dos elementos ou de hierarquias em relação aos integrantes do projeto. Prevalece, nesse nível, a composição figural. Um segundo momento observado anuncia o estabelecimento de relações entre parte e todo, bem como a possibilidade de atribuição de propriedades de programação aos objetos (já diferenciados entre si), denotando-se um encaminhamento gradativo ao pensamento operatório. $\mathrm{O}$ nível superior encontrado a partir das condutas observadas comporta características operatórias, como a classificação dos elementos e a construção de conexões entre estes por meio da realização de coordenações implicativas [7, 9] nas proposições de programação.

É importante reiterar que a identificação de estados sucessivos rumo ao conceito operatório na atividade de programação resulta, inicialmente, de um mapeamento das condutas gerais observadas, não refletindo necessariamente a transição de níveis na conduta de uma mesma criança. Estima-se, contudo, que o estabelecimento de níveis favoreça o acompanhamento dos processos de conceituação mediados pela atividade de programação no contexto do desenvolvimento de Projetos de Aprendizagem. A etapa posterior do estudo prevê o acompanhamento de crianças - por meio da análise de suas produções e da realização de entrevistas clínicas - a fim de verificar a transição de etapas das condutas e validar os níveis a priori encontrados.

\section{Considerações finais}

É crescente o número de pesquisadores, pais e professores que vêm descobrindo as potencialidades do ambiente Squeak Etoys em diversos países. No entanto, seu uso no sistema escolar é apenas incipiente, e sua disseminação, um desafio. Desde as primeiras experiências do Programa UCA, o LEC/UFRGS tem realizado estudos e auxiliado na disseminação da atividade entre educadores e aprendizes no Brasil e em demais países participantes de projetos de distribuição de um computador por aluno na América Latina. As investigações e os resultados alcançados contribuíram para que o programa fosse, na fase atual do PROUCA, um dos softwares disponíveis no laptop adotado pelo governo brasileiro.

A presença do software no laptop e na escola, contudo, está longe de garantir, por si só, um uso profícuo ao desenvolvimento conceitual do aluno. Ao longo das pesquisas realizadas e por meio das referidas experiências na modalidade 1 para 1 , temos constatado que a aplicação do Squeak Etoys, assim como a utilização de demais tecnologias digitais ou ambientes de autoria multimídia, 
garante resultados mais efetivos em relação à construção do conhecimento e ao desenvolvimento conceitual do aluno quando há mudanças pedagógicas na sala de aula. A metodologia de PAs, centrada na ação e autoria do aluno, favorece uma aplicação contextualizada e rica da atividade de programação. Iniciar um projeto de programação a partir de uma curiosidade e de um desejo de pesquisa reais do aprendiz incita-o ao engajamento na busca de soluções para os desafios e as perturbações encontradas. Também facilita o acompanhamento e o auxílio ao aluno em seu processo de conceituação rumo à operatoriedade do pensamento, uma vez que as tentativas, hipóteses e noções apresentadas são manifestas em cada ação no ambiente. Convém destacar o caráter de permanente abertura do processo de construção conceitual, já que um conceito nunca está concluído, podendo desenvolver-se sempre mais, sobretudo na condição de sistemas lógicos que já atingiram as operações formais.

A verbalização oportunizada pela utilização do método clínico-crítico Piagetiano é também fundamental ao pesquisador que deseja acompanhar a lógica e a organização do pensamento do aluno, possibilitando o levantamento de questões pertinentes para a desequilibração e posteriores regulações que conduzam o aprendiz a tomadas de consciência, coordenações implicativas de nível superior e consequentes avanços no que tange à conceituação.

O estabelecimento inicial de níveis de apropriação, presente na seção 6 deste trabalho, é resultado da produção de crianças em Squeak Etoys na segunda fase do Programa PROUCA, iniciada em 2010. De acordo com as produções e as condutas apresentadas, algumas das ideias centrais do Squeak Etoys (oriundas de Linguagens Orientadas a Objetos), como o conceito de "objeto" e de trocas de mensagens entre diferentes objetos, estão longe de serem transmitidas à criança, tampouco podem ser obtidas intuitivamente. Estima-se que, integrado ao contexto de desenvolvimento de Projetos de Aprendizagem e da realização de intervenções com orientação no Método Clínico Piagetiano, o estabelecimento de níveis de apropriação do ambiente favoreça o acompanhamento dos processos de conceituação. O levantamento de condutas regulares, balizado pela tradição do aporte da Epistemologia Genética, constitui-se num instrumento facilitador da identificação de momentos suscetíveis a saltos qualitativos e, portanto, do auxílio a tomadas de consciência dos sujeitos, que possam se refletir em transformações conceituais. Além disso, a classificação das produções das crianças, realizada por meio da observação de condutas regulares por elas manifestas quando em interação com o ambiente, abre caminhos para novas questões de pesquisa na aplicação do Squeak Etoys em contexto escolar. Como vimos, há um caminho de construção percorrido pela criança que se apropria do ambiente de programação (da linguagem, dos objetos, das relações possíveis, etc.), que envolve diversas aprendizagens. Consideramos que a atitude da criança de interesse espontâneo, de envolvimento com a atividade e de permanente desafio - é essencial a esse percurso. Determinados contextos têm se mostrado relevantes ao acompanhamento dos processos de conceituação a partir do interesse genuíno dos sujeitos, entre os quais destacamos o desenvolvimento de Projetos de Aprendizagem e a construção de jogos pela criança.

Com base no exposto, alguns questionamentos devem orientar a sequência da pesquisa: como o desenvolvimento de jogos em Squeak Etoys pode auxiliar no acompanhamento dos processos de conceituação? Quando o sujeito usa o Squeak Etoys para representar questões vinculadas ao objeto de investigação, quais as relações possíveis entre o desenvolvimento conceitual observado na atividade de programação e o desenvolvimento do próprio conceito investigado?

Consideramos, assim, a pertinência da utilização do ambiente Squeak Etoys em sala de aula não como um apoio às práticas didáticas instituídas, mas como um catalisador de mudanças que contribuam para a solução de dificuldades de aprendizagem dos alunos à medida que os auxiliem em problemas reais, levantados segundo o próprio interesse e a necessidade efetivamente manifesta por cada aprendiz. É nesse panorama que a tríade PAs/Squeak Etoys/Intervenções orientadas pelo método clínico-crítico Piagetiano é assumida como um contexto potencialmente rico para o desenvolvimento conceitual e avanços rumo ao pensamento operatório.

\section{Referências}

[1] P. Demo. Questões para a teleducação. Petrópolis, Ed. Vozes, 1998.

[2] L. C. Fagundes, D. Maçada, L. Sato. Aprendizes do futuro: as inovações começaram. Coleção Informática para a Mudança na Educação, Brasília, SEED, MEC, PROINFO, 1999.

[3] M. E. B. Almeida, M. E. B. B. Prado. Indicadores para a formação de educadores para a integração do laptop na escola. In M. E. B. Almeida, M. E. B. B. Prado (Org.). O computador portátil na escola: mudanças e desafios nos processos de ensino e aprendizagem, São Paulo, Avercamp, 2011.

[4] M. Resnick. Rethinking Learning in the Digital Age. MIT MediaLab. 
http://llk.media.mit.edu/papers/rethinkport.doc, 2002.

[5] Programa UCA - Um Computador por Aluno. http://www.uca.gov.br/institucional/projeto.jsp, 2010.

[6] J. Piaget. A equilibração das estruturas cognitivas: problema central do desenvolvimento. Rio de Janeiro, Zahar Editores, 1976.

[7] J. Piaget. Fazer e compreender. São Paulo, Ed. Melhoramentos, 1978.

[8] J. Piaget. O nascimento da inteligência na criança. Rio de Janeiro, LTC Editora, 1987.

[9] J. Piaget. A formação do símbolo na criança: imitação, jogo e sonho, imagem e representação. Rio de Janeiro, Zahar Editores, 1990.

[10] A. Kay. Squeak Etoys: Authoring \& Media. http://www.squeakland.org/resources/articles/arti cle.jsp?id=1008, 2011.

[11] S. Papert. A máquina das crianças: repensando a escola na era da informática, Porto Alegre, Ed. Artmed, 1994. [12] Fundação Pensamento
http://www.pensamentodigital.org.br, 2009.

[13] J. Piaget. A representação do mundo na criança. São Paulo, Ed. Idéias e Letras, 2005.

[14] M. C. Baranauskas. Procedimento, Função, Objeto ou Lógica? Linguagens de programação vistas pelos seus paradigmas. NIED UNICAMP, 1998.

A. Kay. Computer Software. Scientific American, n. 251, http://www.vpri.org/pdf/tr1984001_comp_soft.p df, 1984.

[16]

S. Papert. Mindstorms: Children, Computers and Powerful Ideas. New York, Basic Books, 1980.

[17]

L. C. Fagundes, P. R. F. Mosca. Interação com computador de crianças com dificuldade de aprendizagem: uma abordagem Piagetiana. Arquivos Brasileiros de Psicologia, n. 37, 1985.

[18]

R. A. Nevado. A utilização do microcomputador na pré-escola como prevenção de distúrbios de aprendizagem. In: Psicologia: Reflexão e Crítica, Porto Alegre, v.5, n.1, 1992.

[19]

L. C. Fagundes, C. Maraschin. A linguagem LOGO como instrumento terapêutico das dificuldades de aprendizagem: possibilidades e limites. In: Psicologia: Reflexão e Crítica, Porto Alegre, v. 5, n. 1, 1992.

[20] E. Lindner, B. F. Sperb, L. C. Fagundes. Oficinas de Aprendizagens no Ambiente Computacional Squeak-Etoys. Estudo Experimental no Uso do Laptop em Sala de Aula do Projeto UCA. In: XIX SBIE, Simpósio Brasileiro de Informática na Educação, Workshop 4, Fortaleza, UFC, 2008. 